\title{
APPARENT SHAPE AND SIZE OF THE PUPIL VIEWED OBLIQUELY*
}

BY

\section{K. H. SPRing and W. S. Stiles}

IN studies of the response of the peripheral retina, a knowledge of the apparent shape and size of the pupil for large angles of view is sometimes necessary. By photographing the pupil at various angles in the horizontal meridian from $20^{\circ}$ nasal to $105^{\circ}$ temporal the mean results shown in Table I were obtained for a group of 13 subjects. In the case of the large pupil, the pupil was fully dilated with a mydriatic and the field of view was kept dark until the lightflash for the exposure was given. These results refer therefore to a pupil whose actual size may be taken as constant for all angles of view. The variations of apparent size are attributable solely to the obliquity and to the refraction of the cornea and aqueous. For the small pupil results on the other hand the pupil was free, i.e., no miotic was used, but it was kept small by being permanently exposed to the light source used for the photography. In these circumstances the actual pupil size could not be taken as constant for the various exposures and, for this reason, only the ratio of horizontal and vertical diameters determining the approximate shape of the apparent pupil is reported. The individual variations in shape for both large and small pupils are shown by the plots of this ratio in Figs. 1 and 2.

In view of the angular displacement of the optic axis relative to the visual axis, the mean curves of Figs. 1 and 2 may be expected to be symmetrical about an ordinate at about $5^{\circ}$ temporal. As far as can be judged with only one observational angle on the nasal side, this is the case. It will be noted (column 3 of Table I) that for the large pupil the apparent vertical diameter varies little with angle but shows a maximum at about $80^{\circ}$ temporal.

For a simplified eye consisting of a refracting sphere of index 1.336 and radius $7.8 \mathrm{~mm}$. in which the pupil is imbedded at a distance $3.3 \mathrm{~mm}$. from the "corneal" surface, the calculated apparent areas for various angles of view and for large and small pupils are shown in Fig. 3. The area for observation along the optic axis is taken as unity and allowance is made for a $5^{\circ}$ separation of the optic and visual axes. The mean experimental curve for the large pupil is shown in the same diagram as well as the

* Communicated by the National Physical Laboratory. Received for publication April 15, 1948. 
simple cosine curve which would be obtained if there were no corneal refraction. It is apparent that the calculated values deviate materially from the observed values for angles of view exceeding about $70^{\circ}$.

Good sets of pupil photographs at different angles are reproduced in Figs. 4 and 5. For these, the pupil has a non-zero and fairly well defined area at $105^{\circ}$, the largest angle used. In many cases the interpretation of the large angle photographs is difficult, particularly for brown (pigmented) eyes, where contrast between iris and pupil is low. In the example of Fig. 4 the far edge of the pupil approaches the corneal surface at $70^{\circ}$ to $80^{\circ}$ angle of view but subsequently recedes. Qualitatively, this is what would be expected from the simple theory mentioned above. There is considerable individual variation in the apparent position of the pupil at oblique angles of view.

If it is assumed that the apparent vertical diameter of the small pupil, like that of the large pupil, varies little with angle the average apparent area for pupils of any size and angle of view can be estimated approximately by interpolation. This is done in Table II, which assumes (1) that the relative apparent vertical diameters at different angles are the same for all pupil sizes and correspond to the values for the large pupil given in column 3 of Table I, (2) that, at a given angle, the ratio of horizontal to vrrtical diameters may be taken as a linear function of the apparent pupil diameter for normal view, i.e., linear interpolation between columns 4 and 6 of Table II can be applied, (3) that the eye may be taken as a system symmetrical about an axis (the optic axis) inclined $5^{\circ}$ to the temporal side of the visual axis.

Acknowledgment. The work described above was carried out in the Light Division of the National Physical Laboratory on behalf of the Chief of the Royal Naval Scientific Service, by whose permission this paper is published. 


\begin{tabular}{|c|c|c|c|c|c|}
\hline \multicolumn{6}{|c|}{$\begin{array}{c}\text { APPaRENT Shape and SizE OF PUPIL } \\
\text { TABLE I }\end{array}$} \\
\hline \multirow{2}{*}{$\begin{array}{l}\text { Direction of } \\
\text { view of the } \\
\text { camera with } \\
\text { respect to the } \\
\text { visual axis }\end{array}$} & \multicolumn{4}{|c|}{ Large pupil } & \multirow{2}{*}{$\begin{array}{c}\text { Small pupil* } \\
\begin{array}{c}\text { Ratio of } \\
\text { Hor./Vert. } \\
\text { Diam. }\end{array}\end{array}$} \\
\hline & $\begin{array}{l}\text { Mean Appt. } \\
\text { Hor. Diam. }\end{array}$ & $\begin{array}{l}\text { Mean Appt. } \\
\text { Vert. Diam. }\end{array}$ & $\begin{array}{c}\text { Ratio of } \\
\text { Hor./Vert. } \\
\text { Diam. }\end{array}$ & $\begin{array}{l}\text { Appt. } \\
\text { Area }\end{array}$ & \\
\hline $20^{\circ}$ Nasal & $7 \cdot 13 \mathrm{~mm}$ & $7.94 \mathrm{~mm}$ & 0.90 & $44.4 \mathrm{~mm}^{2}$ & 0.91 \\
\hline $0^{\circ}$ & $7 \cdot 69$ & 7.84 & 0.98 & $47 \cdot 3$ & $1 \cdot 00$ \\
\hline $35^{\circ} \mathrm{Temp}$ & $7 \cdot 01$ & $7 \cdot 83$ & 0.90 & $43 \cdot 1$ & 0.90 \\
\hline $55^{\circ} \mathrm{Temp}$ & $5.72^{\circ}$ & $7 \cdot 99$ & 0.72 & $35 \cdot 9$ & 0.73 \\
\hline $70^{\circ}$ Temp. & .4 .43 & $8 \cdot 15$ & 0.54 & $28 \cdot 3$ & 0.53 \\
\hline $80^{\circ}$ Temp. & $3 \cdot 25$ & $8 \cdot 19$ & 0.40 & $20 \cdot 9$ & 0.40 \\
\hline $90^{\circ}$ Temp. & $1 \cdot 18$ & $8 \cdot 15$ & 0.23 & $12 \cdot 0$ & 0.28 \\
\hline $100^{\circ}$ Temp. & 0.75 & $7 \cdot 72$ & 0.10 & $4 \cdot 5_{3}$ & 0.15 \\
\hline $105^{\circ}$ Temp. & 0.25 & $7 \cdot 44$ & 0.03 & $1.4_{6}$ & 007 \\
\hline
\end{tabular}




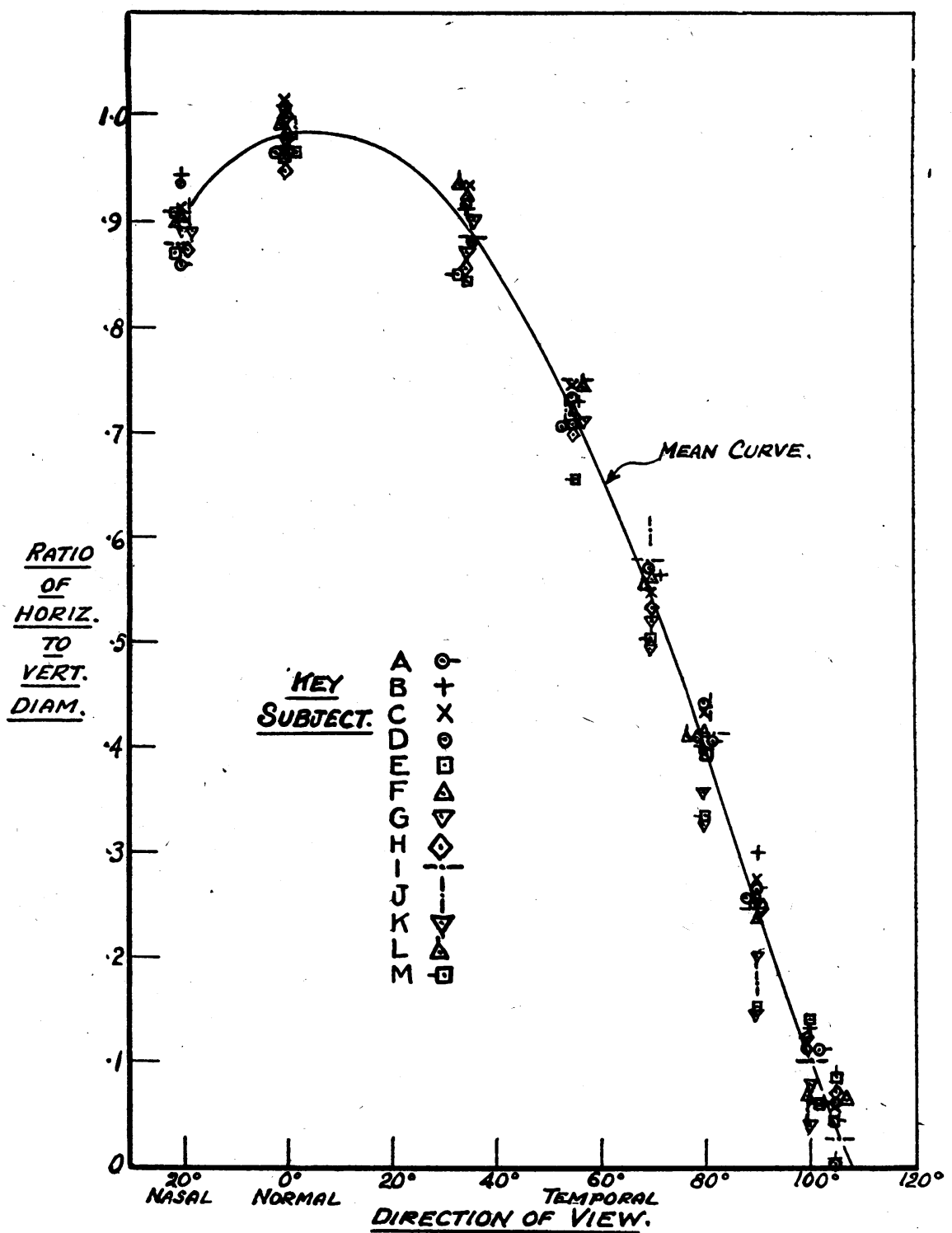




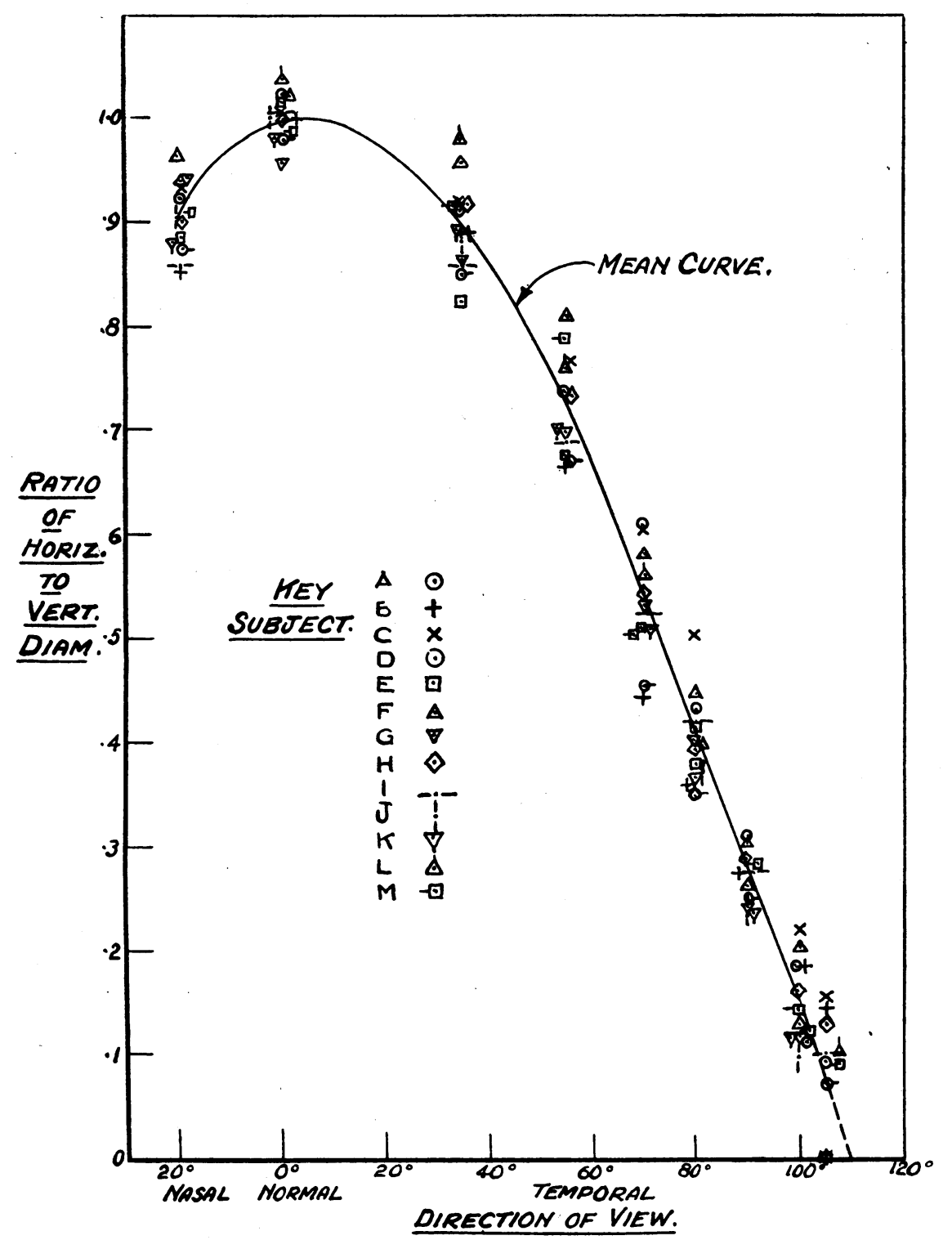




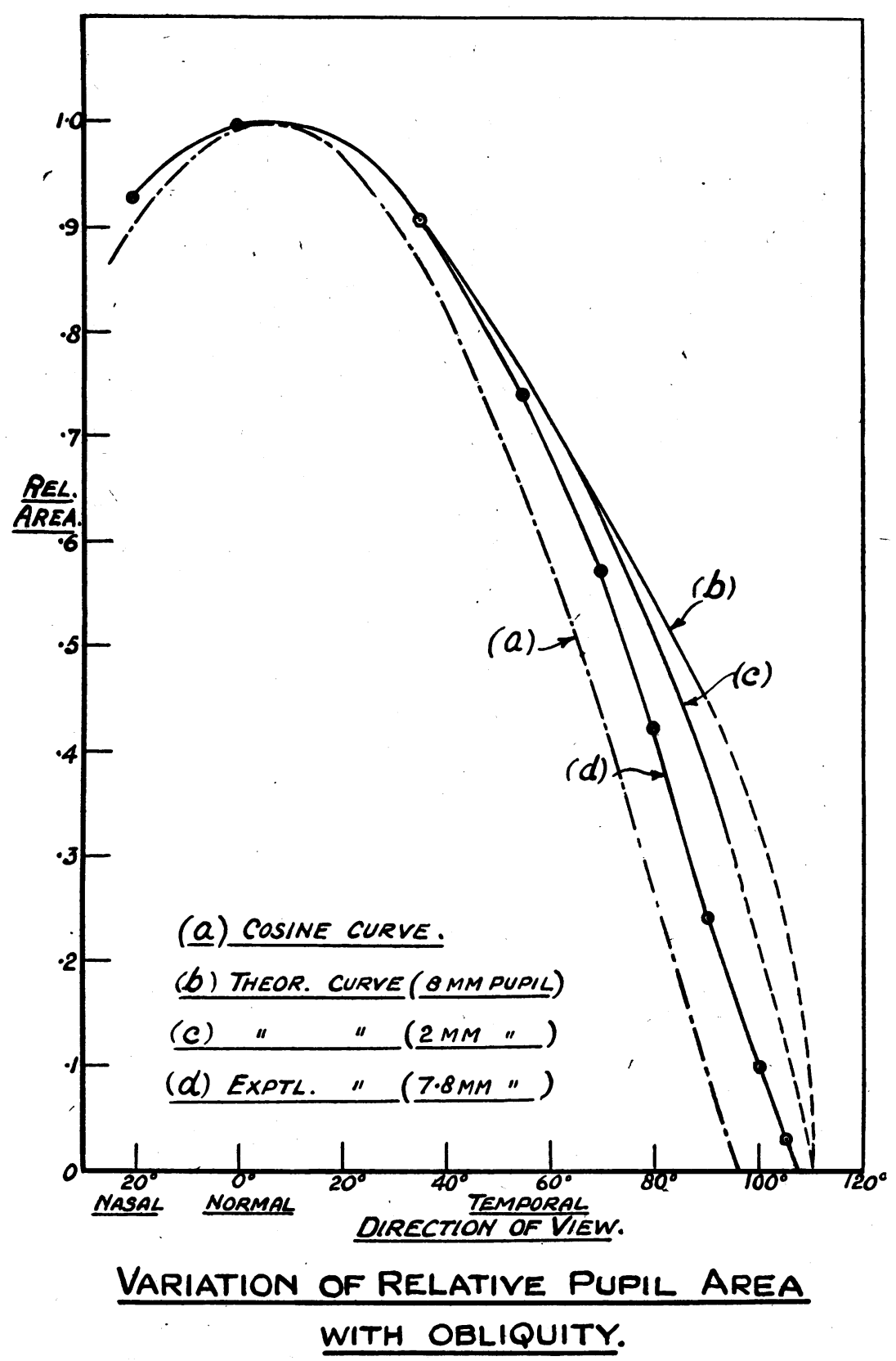

Fig.3. 
Àpparent Shape and Size of Pupil Viewed Obliguely 353

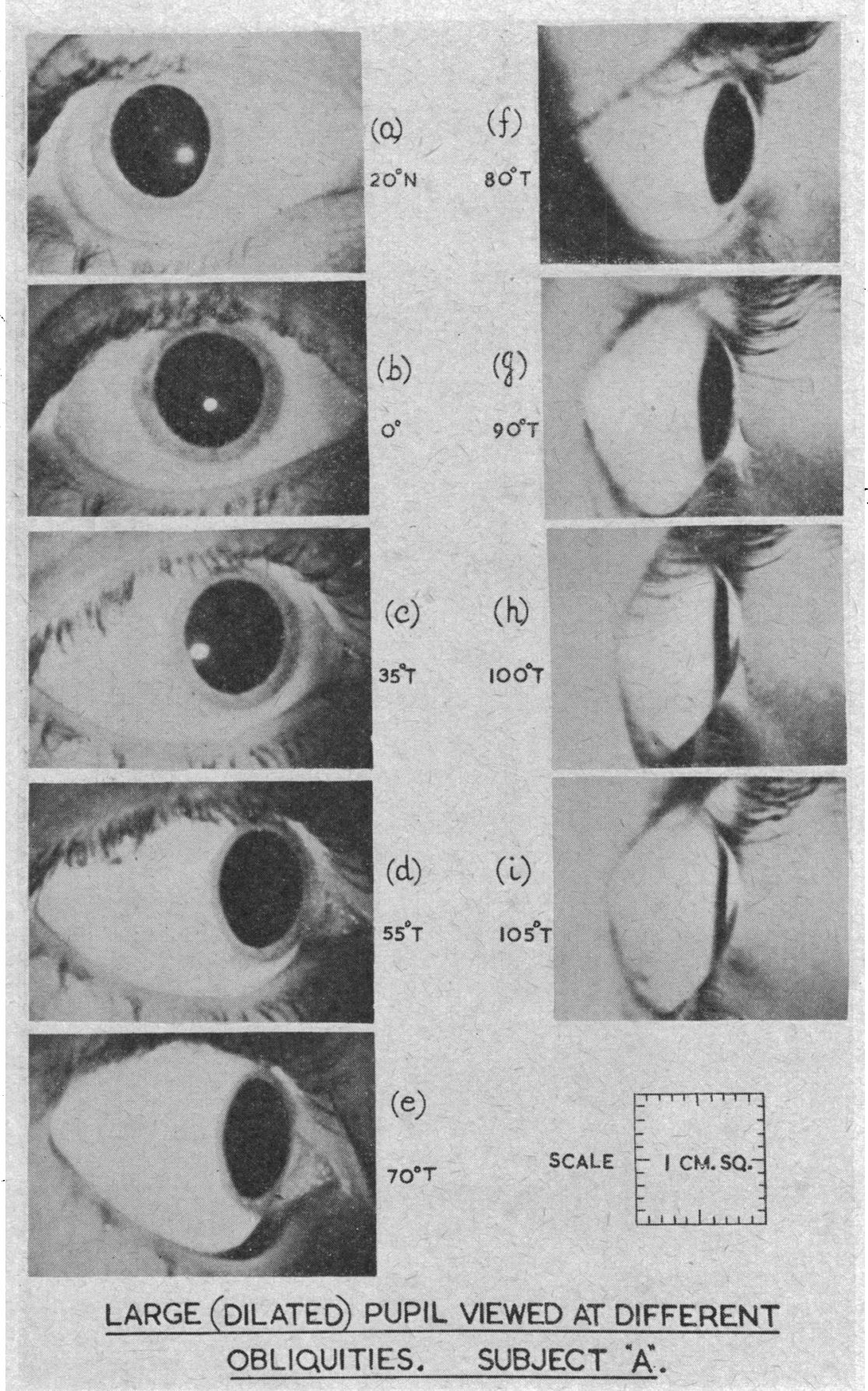

FIG. 4. 
